\section{Quantitative Analysis by the Variation of the Specific Activity of an Added Radioactive Isotope}

In a mixture of ions, one of them can be estimated by adding to the solution its radioactive isotope. The specific activity is modifled, and one can deduce from that modification the concentration of the inactive ion initially present.

Various researches have already been undertaken in this direction. Delépine ${ }^{1}$ in 1925 indicated the possibility of estimating the quantities of optical isomers in a given sample. Later, Hevesy and Hobbie ${ }^{2}$ estimated traces of lead in rocks using its natural isotope radium D as an indicator. In 1939 Schoenheimer, Ratner and Rittenberg ${ }^{3}$, as an indicator. In 1939 Schoenheimer, Ratner and Rittenberg ${ }^{3}$, aid of heavy isotopes, and Rittenberg and Forster ${ }^{5}$ gave detailed aid of heavy isotopes, and Rittenb

The artiflcial radioactive isotopes which had not yet been employed in analysis naturally afforded great interest. In this flrşt account, we review briefly the results obtained in the estimation of potassium effected in the presence of lithium and sodium.

To the solution containing these three elements a measured quantity of ions $\left(K^{*}+K\right)$, having a known activity, was added. From the new mixture the potassium is precipitated as an insoluble salt such as the perchlorate. One part of it is isolated and weighed, and from the new activity the quantity of inactive ions initially present in the solution is deduced. The advantage of this method is obvious: the precipitation does not need to be quantitative, it is sufficient to isolate one part of the salt in a pure state to flnd out its specifle activity.

our determination of quantities of $\mathrm{K}$ from $1-0.1 \mathrm{gm}$. (in potassium chloride) mixed with $13.6 \mathrm{gm}$. of salts (sodium and lithium nitrates) gave results accurate to within 1 per cent. One can also consider the estimation of complex organic compounds such as the alkyl halides, compounds of arsenic, sulphur, etc. The estimation of proteins containing phosphorus should be interesting, as the half-life of radiophosphorus is long (14 days). The analysis of iodine compounds of the thyroid gland will doubtless be feasible by this method, using iodine of half-life ( 8 days).

Laboratoire de Chimie Nucléaire,

PIERRE SUE.

Collège de France, Paris.

I Delépine, C.R. Congr. Soc. Sav. (1925)

2 Hevesy and Hobbie, Z. anal. Chem., 88, 1 (1932).

${ }^{3}$ Schoenheimer, Ratner and Rittenberg, J. Biol. Chem., 130, 703 (1939)

Ussing, Nature, 144, 977 (1939)

s Rittenberg and Forster, J. Biol. Chem., 133, 737 (1940).

\section{A New Flame Phenomenon}

IN the course of an examination during 1938 of the effect of the quality of coal gas upon the completeness of combustion in domestic gas appliances, a speedy method of determining total air requirement was developed. progressive reduction in the air/gas ratio the violet-blue flame gradually increases in length, while the intensity of the colour increases to \& maximum and then decreases. Finally, the whole flame is suddenly combustion of the gas.

The name 'calyx'- - owing to its resemblance to the calyx of a flower -has been given to the violet-blue flame. The violet-blue colour appears to be the more intense the higher the sulphur content of the gas. In collaboration with Dr. E. C. W. Smith, a spectrogram of the calyx flame obtained with town gas has been taken and this of the very clearly the vo other lines are visible. Dr. G. Whittingham ${ }^{1}$ has observed the $\mathrm{S}$. lines in a spectrogram of a coal gas flame to which sulphur dioxide has been added.

Consideration of the equilibria existing in the flame produced by a consideration of the equilibria existing in the flame produced by a mount of air suggests that the sulphur may arise from the reaction:

$$
2 \mathrm{SO} \rightleftarrows \mathrm{SO}_{2}+\frac{1}{2} \mathrm{~S}_{2} \text {. }
$$

At the temperature existing in the flame, this system is composed predominantly of SO, and a considerable fall in temperature is necessary for the formation of $\mathrm{S}_{2}$ in sufficient concentration to give a visible the calyx.

It is probable that the violet-blue zone that can be seen as a thin line beneath a kettle when an aerated coal gas flame impinges upon it is essentially the same phenomenon. The local conditions under which it is formed are similar to those necese local conditions under a strongly developed calyx, namely, a deficiency of air and a relatively low temperature.

Experiments were made with hydrogen and air, in both of which the sulphur concentration was known to be less than 0.5 parts in two million parts by weight; and the violet-blue flame was detectable although it was more diffuse than the well-deflned calyx flames obtained with coal gas and air. Another striking difference is that with hydro. gen the violet-blue flame appears to be in a state of considerable gen the violet-blue flame appears to be in a state

Measurements were made with various coal gases, for the detailed analyses of which we are indebted to the Gas Research Board. Gas. and air-rates were measured by means of calibrated flow meters, both gas and air being saturated with water vapour at room tempers. ture. Starting with the mixture on the air-rich side, the air-rate ws: gradually decreased, and at the point of appearance of the calyx a sample of the products of combustion was taken for analysis. Th existence of the calyx is sensitive to changes of the proportion of air of less than 1 per cent of the total air requirement. The results of th tests are given in the table appended.

From the point of view of appliance design, the $\mathrm{CO} / \mathrm{CO}_{2}$ ratios are of direct signiflcance. These are all within the range normally regarded in the gas industry as indicating satisfactory combustion, and the corresponding air/gas ratios therefore give the minimum proportion of air required to burn the gas completely. The air/gas ratios calculated from analytical data approximate to the observed values.

\begin{tabular}{|c|c|c|c|c|c|c|c|c|c|}
\hline \multirow[b]{2}{*}{ Kind of gas } & \multirow{2}{*}{$\begin{array}{c}\text { Gross C.V. } \\
\text { B.Th.U. } \\
\text { per cu. ft. }\end{array}$} & \multirow{2}{*}{$\begin{array}{l}\text { A.T.B. No. } \\
\text { (B scale) }\end{array}$} & \multirow{2}{*}{$\begin{array}{l}\text { Sulphur } \\
\text { grains per } \\
100 \mathrm{cu} . \mathrm{ft} .\end{array}$} & \multicolumn{3}{|c|}{ Products } & \multicolumn{3}{|c|}{ Air/Gas ratio } \\
\hline & & & & $\begin{array}{c}\mathrm{CO}_{2} \\
\%\end{array}$ & $\begin{array}{l}\mathrm{O}_{2} \\
\%\end{array}$ & $\underset{\text { ratio }}{\mathrm{CO} / \mathrm{CO}_{2}}$ & Observed & & \\
\hline Carburetted water gas & 433 & $21 \cdot 5$ & 10 & $16 \cdot 8$ & $0 \cdot 1$ & 0.015 & $3 \cdot 89$ & $\begin{array}{l}(a) \\
3 \cdot 75\end{array}$ & $\begin{array}{c}(b) \\
3 \cdot 81\end{array}$ \\
\hline Vertical retort gas $-C$ & 451 & $33 \cdot 0$ & 24 & $11 \cdot 8$ & 0.5 & 0.0059 & $3 \cdot 89$ & $3 \cdot 83$ & $3 \cdot 86$ \\
\hline Vertical retort gas $-D$ & 449 & $31 \cdot 3$ & 20 & $12 \cdot 3$ & 0.3 & 0.0078 & $3 \cdot 87$ & $3 \cdot 77$ & $3 \cdot 84$ \\
\hline Town gas $-D$ & 449 & $29 \cdot 1$ & 18 & $13 \cdot 1$ & $0 \cdot 2$ & 0.0070 & $3 \cdot 82$ & $3 \cdot 78$ & $3 \cdot 84$ \\
\hline $\begin{array}{l}\text { Vertical retort gas- } E \\
\quad \text { (unstripped) }\end{array}$ & 485 & $39 \cdot 2$ & 33 & $12 \cdot 1$ & $0 \cdot 1$ & 0.010 & $4 \cdot 17$ & $3 \cdot 97$ & $4 \cdot 23$ \\
\hline
\end{tabular}

(a) Calculated from the gas analysis, assuming the unsaturated hydrocarbons to be $\mathrm{C}_{3} \mathrm{H}_{\mathbf{6}}$.

(b) Calculated by the formula, developed by Mr. J. W. Wood

$$
\text { C.V. } \times \frac{1.055}{100}-0.97+(0.97 \times \% \text { inerts })-\frac{\% \text { oxygen }}{21}
$$

Previously this flgure had normally been obtained by one of two methods: $(a)$ calculation from the composition of the gas; $(b)$ direct combustion by explosion or catalytic oxidation. In the method to be described, the air required per cubic foot of gas for complete com bustion can be determined directly by measurement of rates of flow of air and gas. The flame itself provides a satisfactory criterion when the correct ratio is attained.

The apparatus is essentially a simple tube burner to which a mixture of air and gas in controlled proportions is delivered. The burner is set in an enclosure of which the exit is made sufficiently small to maintain a slight excess of pressure over the external atmosphere and prevent back diffusion of air to the flame. The flame is, therefore, surrounded by its own products of combustion. The enclosure is formed by a tall glass cylinder sealed to a solid base supporting the burner. At the top of the cylinder there is a loosely fltting lid with two smal holes.

With excess air the flame, as seen in a darkened room, has a lilaccoloured inner cone surmounted by an envelope of paler lilac shade. At the top of the outer envelope the colour changes to a reddish hue. When the ratio of air to gas is slowly reduced there comes a point where the outer envelope suddenly increases about three-fold in height. Further slight reduction in the air/gas ratio causes the height of the outer envelope to decrease again, and this is accompanied by the appearance of a small violet-blue flame at the base of the main flame, there being a dark space between the two flames. With further
Observations with gases ranging from 347 to 522 B.Th.U. per cu. ft. indicate that the method can be applied to any town gas. F. BRINSLEY.

Radiation, Ltd.

Aston, Birmingham 6.' Feb. 7.

' Nature, 158, 207 (1945).

\section{A New Spectrographic Spark Source}

ABOUT a year and a half ago, our attention was directed to the relative instability of the condensed spark sources generally in use for quantitative spectrographic analysis. Consequently, work was carriod out with the object of stabilizing the electrical excitation condition in the analytical gap. The investigation led us to consider two general types of excitation circuits, namely, the high-voltage high-power circuit and the low-voltage controlled A.c. arc. In both these circuits the discharge is initiated by means of a synchronized trigger-circuit employing enclosed auxiliary spark gaps of the 'Trigatron' type (s three-electrode gap enclosed in a high-pressure argon-oxygen mixture). The control of the main discharge by means of an auxiliary gap was originally suggested by Feussner ${ }^{1}$, who used a synchronous rotary
spark gap. The attainment of satisfactory operation of the inter. 